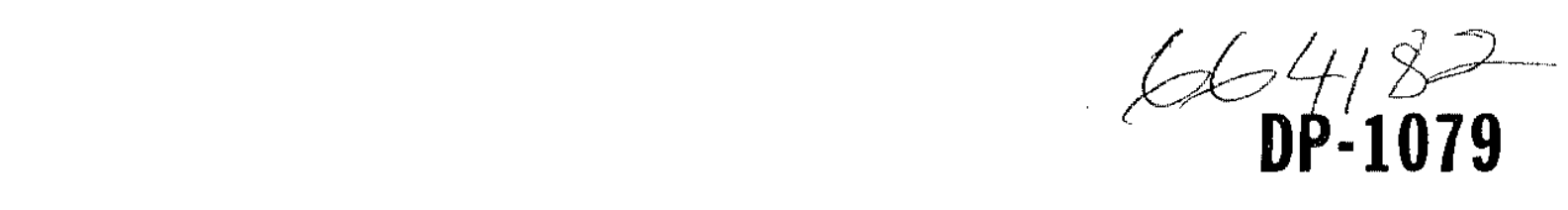

AEC RESEARCH AND DEVELOPMENT REPORT

\title{
SOLID-STATE PLUG-IN CIRCUITS AS INSTRUMENT BUILDING BLOCKS
}

W. J. WOODWARD

SRL

RECHOD COPY

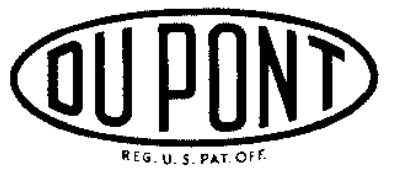

Savannah River Laboratory

Aiken, South Carolina 


\section{LEGAL NOTICE}

This roport wee prepered an an eccount of Government sponsored work. Nelther the United Atates, nor the Comminaton, nor any perton acting on behalt of the Commjeston:

A. Wekes any warranty or representellion, expressod or Implied, with respect to the accurecy, completenese, or unofulness of the information contatinod in thit roport, or that the une

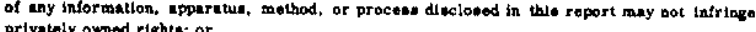
privately owned rightes; or

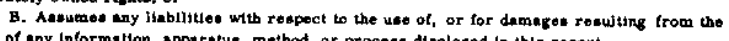
a of any lntormation, apparatus, method, or process discloued in thes repoxt.

As waed in the ebove. "perton scting os behalf of the Commineson" Includen any emsployee or contractor of the Commisalon, or employee of such confractor, to the exient that euch employee or contractor of the Comminstion, or employee of euch contractor prepares. with the commieston, or hla employment with ouch contractor.

Printed in the United States of America Avaliable from

Clearinghouse for Federal Scientiflc and Techntcal Information National Bureau of Standards, U. S. Department of Commerce Springfield, Virginia 22151

price: Printed Copy $\$ 3.00$; M1croriche $\$ 0.65$ 


\title{
SOLID-STATE PLUG-IN CIRCUITS AS INSTRUMENT BUILDING BLOCKS
}

\author{
by \\ William J. Woodward
}

Approved by

D. E. Waters, Manager

Laboratory Operations and Services Division

January 1967

E. 1. DU PONT DE NEMOURS \& COMPANY SAVANNAH RIVER LABORATORY

AIKEN, S. C. 29801

CONTRACT AT(07.2).1 WITH THE

UNITED STATES ATOMIC ENERGY COMMISSION 


\section{ABSTRACT}

Seven standard solid-state circuits were developed for use in radiation instrumentation. These circuits are a pulse amplifier, a varlable discriminator, a pulse-shaping univibrator, a counting tube (dekatron) driver, a count rate meter, and multiple range and time constant clrcuits to operate with the count rate meter. These circuits may be combined to make instruments for specific needs. 


\section{CONTENTS}

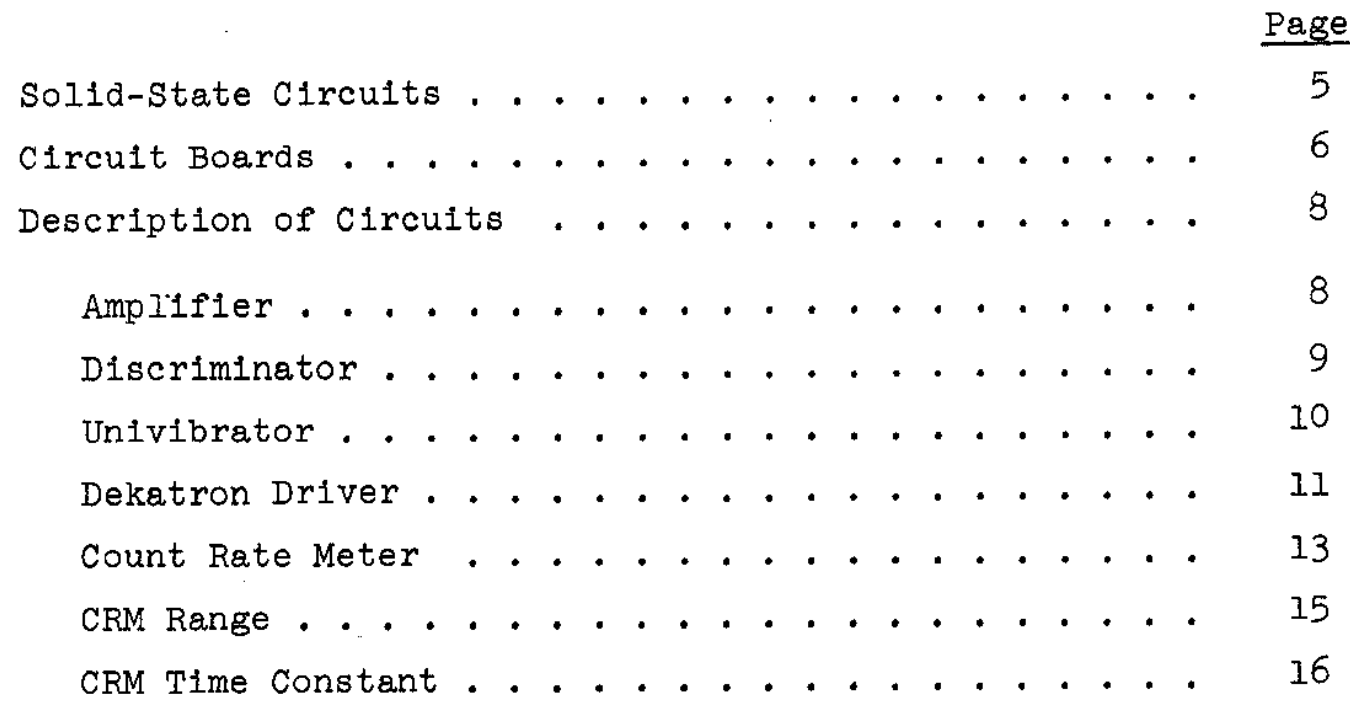

\section{LIST OF FIGURES}

\section{Figure}

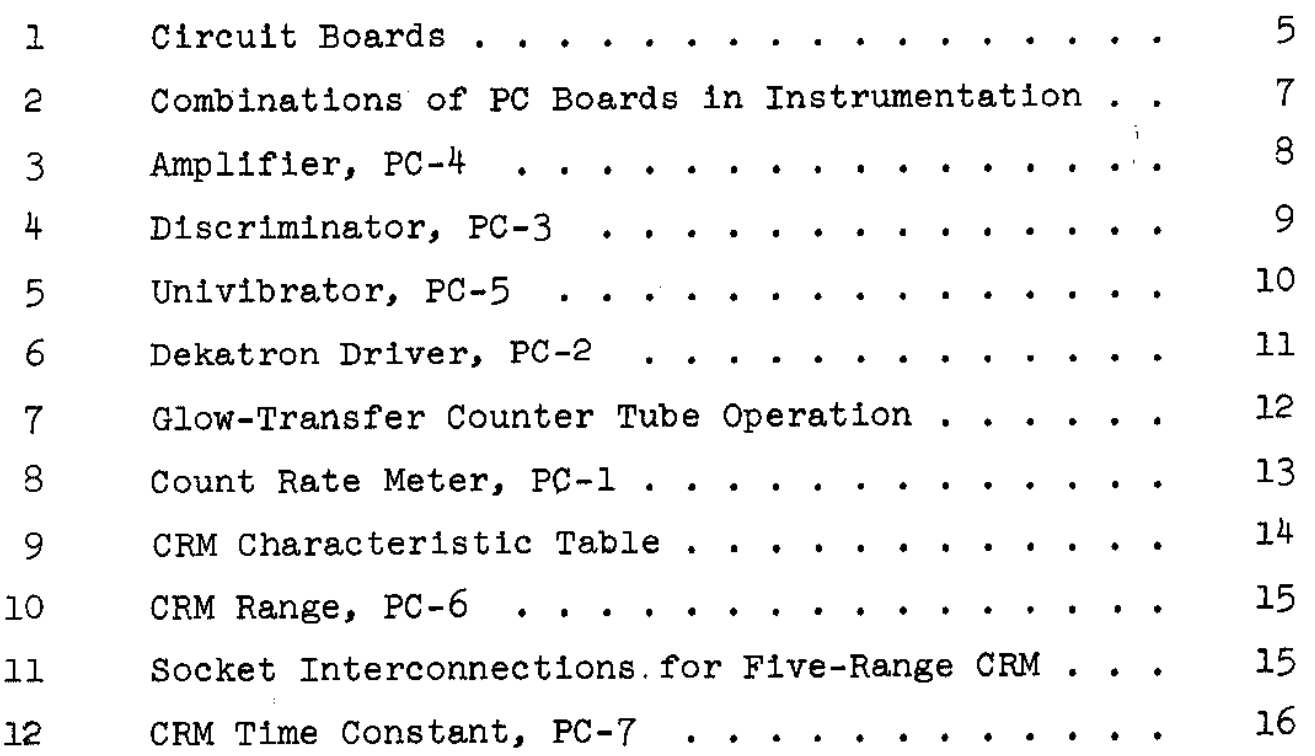




\section{SOLID.STATE PLUG-IN CIRCUITS AS INSTRUMENT BUILDING BLOCKS}

\section{SOLID - STATE CIRCUITS}

Solid-state components have replaced vacuum tubes in many applications for increased reliablility and decreased size. Experience gained at the Savannah River Laboratory in the application of transistors, diodes, and switching devices led to the development of seven standard solid-state circuits that can be used in various combinations to form basic radiation measuring and indicating instruments.

The numbers $\mathrm{PC}-1$ through $\mathrm{PC}-7$ assigned to the circuits are unrelated to their development or use (Fig. I). Standard components (1/2-watt resistors, etc.) are used wherever possible, but miniature components are used where space is limited.
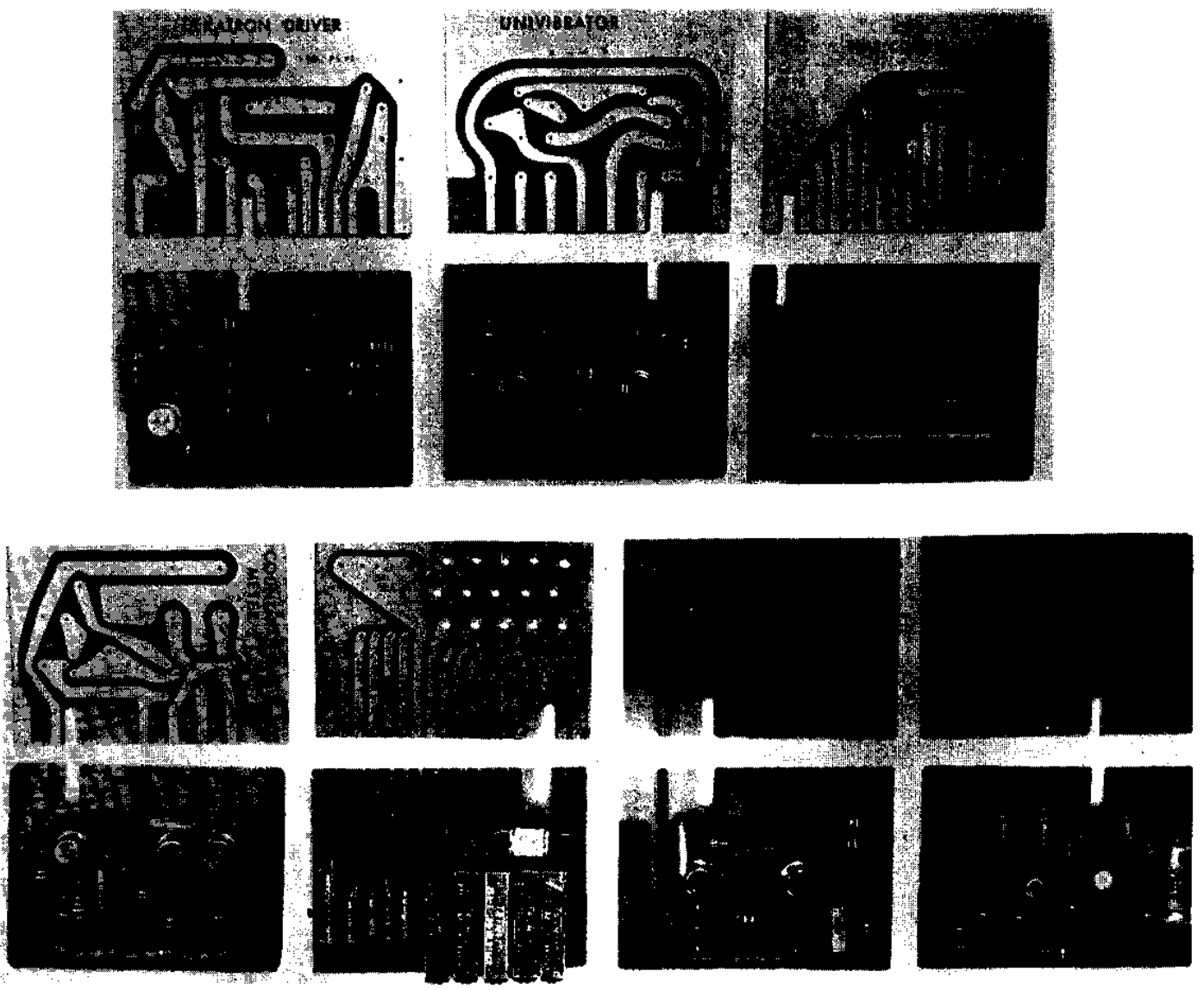

FIG. I CIRCUIT BOARDS 
The PC-series circuits require a slightly higher power supply voltage than some transistor circuits. This voltage allows outputs of sufficient amplitude to drive vacuum tube devices, and also allows solid-state switching of control relays. A regulated power supply may be constructed easily, using a 39-volt regulator alode.

Various combinations of the PC-series circuits have been used (Fig. 2), and individual circuits have been modifled for special applications. Approximately two hundred of these circuits have been used at the Savannah River Laboratory over a two-year period; none have falled, and operation has been entirely satisfactory.

\section{CIRCUIT BOARDS}

An etched circuit board $2-1 / 4$ in. $x 3$ in. $x 1 / 16$ in. is used because it is convenient for most of the basic circuits, and it fits a standard connector. These circuit boards can be mass produced since 16 boards can be cut from standard $9 \times 12-i n$. stock with no waste.

The circuit boards are made by drawing the circuit layout four times its actual size, then photographically reducing the drawing to actual size. A $9 \times 12-1$. composite of 16 negatives is used to expose a sheet of glass-epoxy/copper laminate that is coated with photo resist. After the exposed $9 \times 12-1 n$. sheet is developed and etched, the 16 boards are sawed apart. Each circuit is identified by lettering etched into the conductor side.

The completed circuit boards plug into standard bifurcatedcontact connectors (Cinch-Jones 251-36A-30) which have been proven reliable and safe. (The terminals on only one side may be wired so that a reversed board makes no electrical connections.) Each board is notched in one of its terminal positions, and the corresponding socket position is filled with a plastic nib supplied by the connector manufacturer. Since even-numbered positions are keyed, the notched boards cannot be inserted into the wrong sockets, even when reversed. 


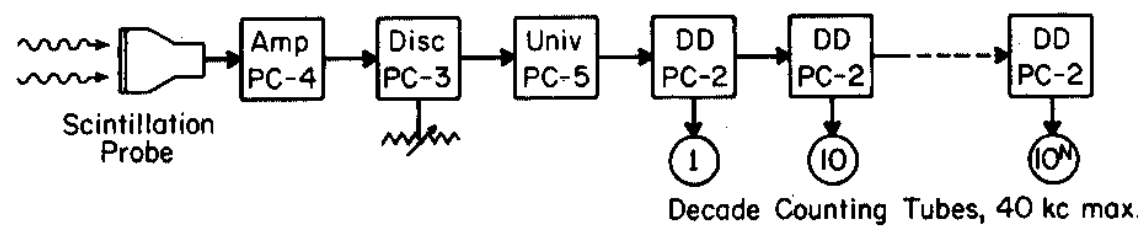

1. RADIATION COUNTER

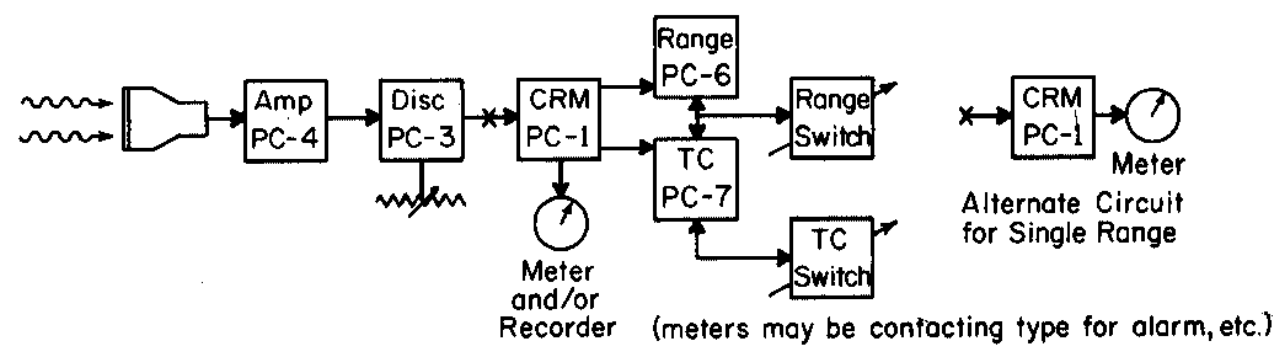

2. RADIATION RATEMETER, MULTI-RANGE

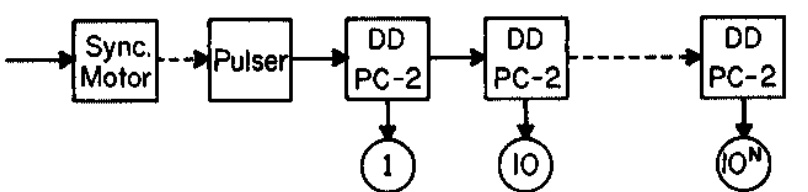

Counter Tubes
Counter pube cathode voltage sensing circuits may be odded for preset time control.

3. DIGITAL CLOCK OR TIMER

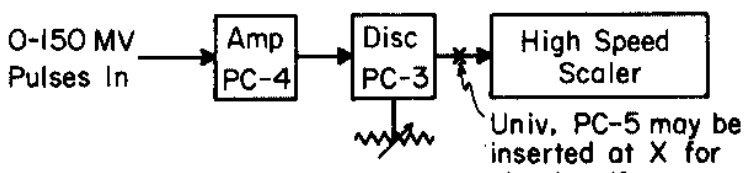

4. HIGH-SPEED PULSE COUNTING shaping if necessary

$\begin{array}{ll}\text { Amp }=\text { Amplifier } & \text { Disc }=\text { Discriminotor } \\ C R M=\text { Count Rate Meter } & \text { TC } * \text { Time Constant } \\ \text { DD }=\text { Dekotron Driver } & \text { Univ } \text { : Univibrator }\end{array}$

FIG. 2 COMBINATIONS OF PC BOARDS IN INSTRUMENTS 


\section{DESCRIPTION OF CIRCUITS}

\section{AMPLIFIER}

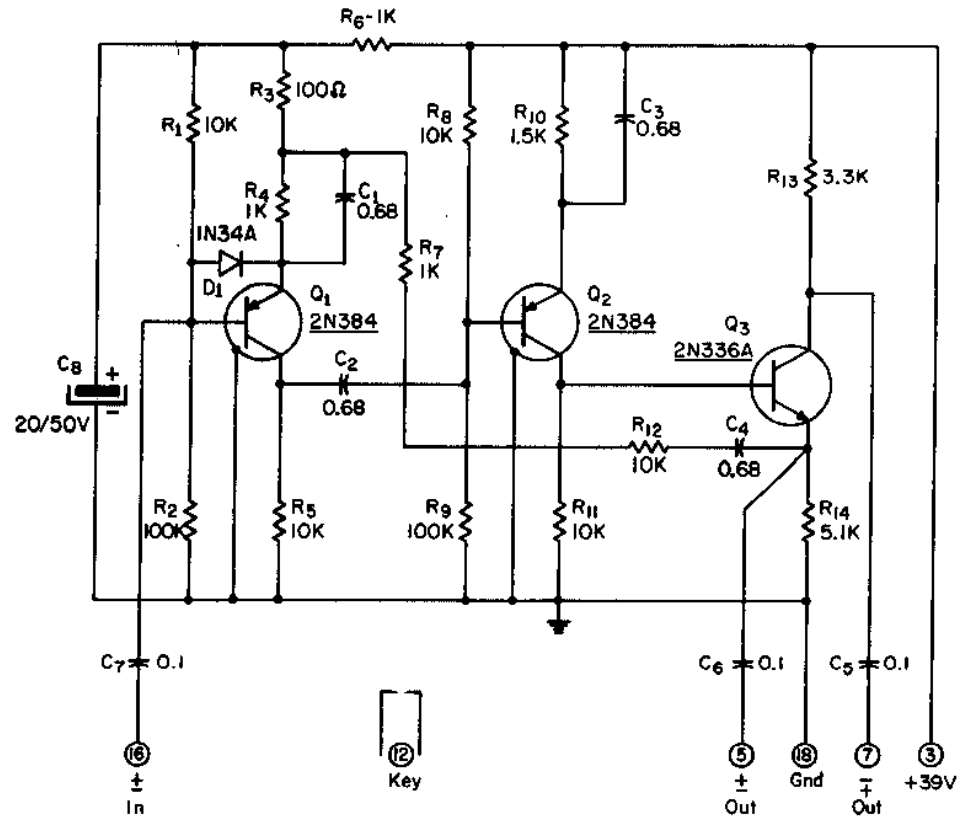

FIG. 3 AMPLIFIER, PC. 4

Germanium drift transistors $\left(Q_{1}\right.$ and $\left.Q_{2}\right)$ were used for their high frequency response characteristics because the amplifier is to handle fast-rising pulses from scintillation detectors. Since all other circuits in this series require a positive power supply, the PNP amplifier stages are "upside down" (with collectors toward ground) so they can operate from the same supply. $Q_{1}$ and $Q_{2}$ are cascaded common-emitter stages, with $Q_{2}$ directly coupled to a silicon phase splitter, $Q_{3}$. Negative feedback, which limits overall amplifier gain to about 100 , is applied from $Q_{3}$ to $Q_{1}$ via $C_{4}, R_{12}$, $R_{7}, R_{3}$, and $C_{1}, R_{12}, R_{7}$, and $R_{3}$ form a voltage divider, while $C_{1}$ bypasses bias resistor $R_{4}$. Unbalanced load resistors $R_{13}$ and $R_{14}$ compensate for different impedance levels at the emitter and collector of $Q_{3}$, and provide normal or inverted outputs through $\mathrm{C}_{5}$ or $\mathrm{C}_{8}$. Diode $\mathrm{D}_{1}$ prevents base-emitter breakdown in $Q_{1}$ from large positive pulses.

High-frequency response is greater than 100 megahertz, but Iow-frequency response falls off below 1 kllohertz because of the relatively small coupling and bypass capacitors. Gain is stable from under $10^{\circ} \mathrm{C}$ to over $50^{\circ} \mathrm{C}$. Signals below 130 millivolts are amplified without distortion. Signals of several volts do not harm the amplifier, but overload recovery time increases with signal amplitude. 


\section{DISCRIMINATOR}

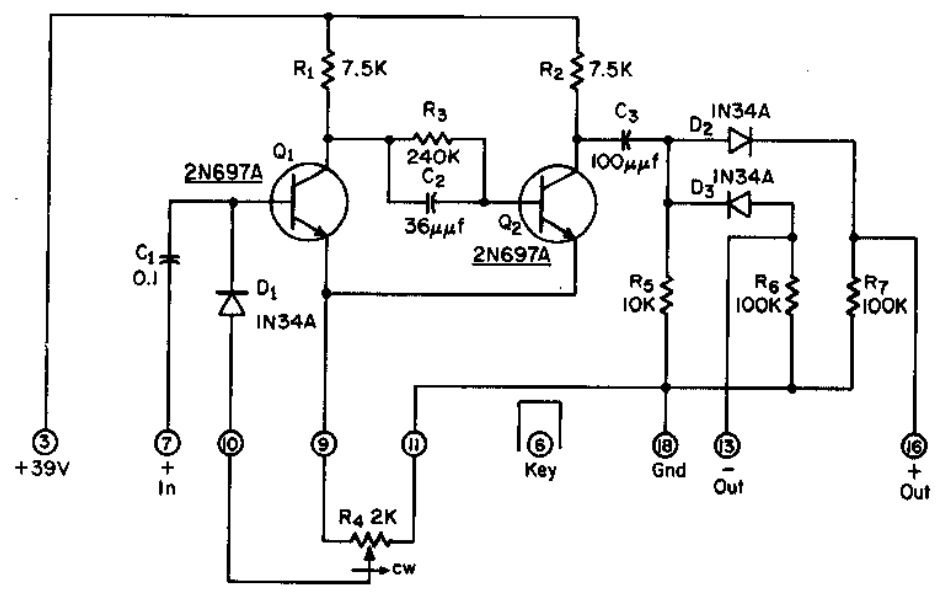

FIG. 4 DISCRIMINATOR, PC -3

A pair of silicon NPN switching transistors is used in a modified Schmitt trigger circuit. $Q_{2}$ is biased "on" through $R_{1}$ and $R_{3} ; Q_{1}$ is blased "off" because the slider voltage of $R_{4}$ is more negative than that of the $Q_{I}$ emitter. ( $R_{4}$ is not on the board, but is connected externally through Terminals 9,10 , and 11. For fine discriminator control a 10-turn potentiometer is recommended.) Incoming positive pulses are developed across diode $D_{1}$, and those exceeding the base-emitter reverse bias cause $Q_{1}$ to conduct. Then the $Q_{1}$ collector voltage becomes less positive, and this negative swing is transferred to the $Q_{2}$ base through $\mathrm{C}_{2}$. Regenerative action takes place (as $Q_{2}$ conducts less) via emitter coupling, and the state is rapidly reversed with $Q_{1}$ turning completely "on" while $Q_{2}$ turns completely "off." This state prevails unt1l the $Q_{1}$ base voltage falis below the reverse bias point; then the original states of $Q_{1}$ and $Q_{2}$ are restored by reverse action.

The output at the $Q_{2}$ collector is, therefore, a positive square pulse of about 30-volt amplitude with the same width as the input pulse at the discriminator trigger level. This square pulse is differentiated by $\mathrm{C}_{3}$ and $R_{5}$; the positive spikes are developed across $R_{7}$ through $D_{2}$, and the delayed negative spikes are developed across $R_{8}$ through $D_{3}$. 


\section{UNIVIBRATOR}

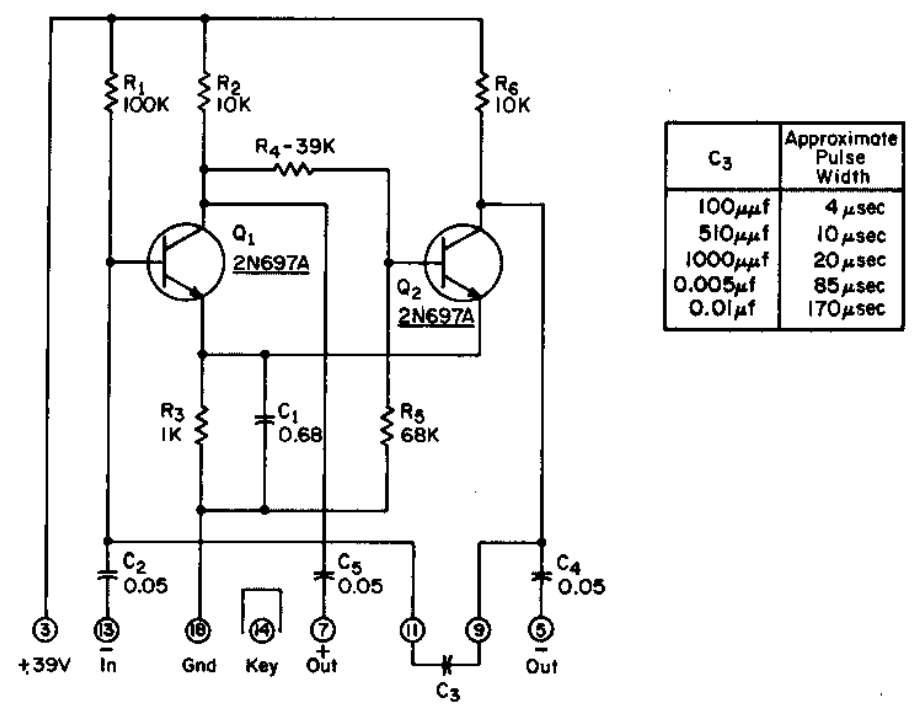

FIG. 5 UNIVIBRATOR, PC-5

A triggered multivibrator, or "one-shot," Is made with a pair of silicon switching transistors. This circult provides pulses of constant size and shape to reliably drive counting circuits.

In this circuit, $Q_{I}$ is blased "on" through $R_{1}$. The $Q_{1}$ emitter current develops a more positive voltage at the upper end of $R_{3}$ than is present at the $Q_{2}$ base through voltage divider $R_{4}$ and $R_{5}$; therefore $Q_{2}$ is "off." A short negative input pulse, such as the negative spike from the discriminator output, is applied to the $Q_{1}$ base through $C_{2}$. This causes $Q_{1}$ to conduct less; consequently, the voltage across $R_{4}$ and $R_{5}$ rises. As $Q_{2}$ 's base voltage increases, $Q_{2}$ begins to conduct and 1ts collector voltage decreases. This negative swing of the $Q_{2}$ collector is applied as regenerative feedback to the $Q_{1}$ base through $C_{3}$ (external to the board), causing the change of state to proceed to saturation. $\left(C_{1}\right.$ bypasses $R_{3}$ to prevent emitter coupling effects during this action.) At saturation, the input spike has disappeared and $C_{3}$ must discharge through $R_{1}$ until $Q_{1}$ begins to conduct again. $R_{1}$ is chosen to provide saturation bias in the rest state; $C_{3}$ is chosen for the desired pulse width. Reset to the rest state occurs in the reverse manner after the $R_{1}-C_{3}$ time delay has elapsed, and the resulting pulse output (positive at the collector of $Q_{1}$, negative at $Q_{2}$ ) is about 30 volts in amplitude with widths corresponding to the $\mathrm{C}_{3}$ values shown in the table of Fig. 5. 


\section{DEKATRON DRIVER}

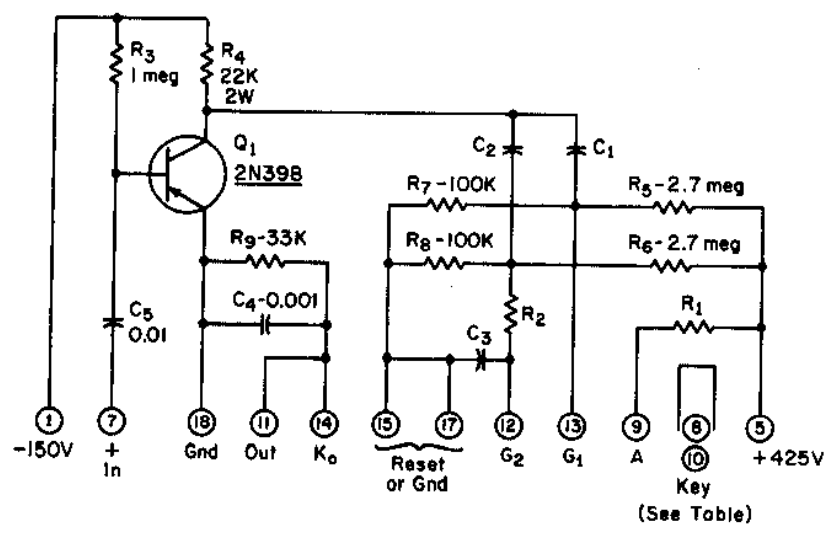

\begin{tabular}{|c|c|c|c|c|c|c|c|}
\hline $\begin{array}{c}\text { Moximum } \\
\text { Frequency }\end{array}$ & Tube Types & Key Way & $R_{1}$ & $R_{2}$ & $C_{1}$ & $C_{2}$ & $C_{3}$ \\
\hline $4 \mathrm{KC}$ & $\begin{array}{l}6 S-10 \mathrm{C} \\
6802 \\
7978\end{array}$ & Term (9) & $820 \mathrm{~K}$ & $68 \mathrm{~K}$ & $0.004 \mu \mathrm{f}$ & $0.01 \mu \mathrm{f}$ & $510_{\mu \mu \mathrm{f}}$ \\
\hline $40 \mathrm{KC}$ & $\begin{array}{l}8262 \\
6909\end{array}$ & Term (1) & $330 \mathrm{~K}$ & $22 \mathrm{~K}$ & $0.001 \mu \mathrm{f}$ & $0.004 \mu \mathrm{f}$ & $150 \mu \mu \mathrm{f}$ \\
\hline
\end{tabular}

FIG. 6 DEKATRON DRIVER, PC-2

A germanium PNP switching transistor is operated in saturation (conducting) from a -150-volt supply. Most of this voltage is dropped across the 2-watt collector resistor $R_{4}$, with only about a 2-volt drop from $Q_{I}$ collector to emitter. A positive input pulse of I volt at the base is capable of turning $Q_{1}$ "off," causing its collector potential to move rapidly toward the supply voltage. Ioading and collector-base leakage combine to limit the actual pulse amplitude to about -100 volts. These pulses are the same width as the input pulses, and are coupled through $\mathrm{C}_{1}$ and $\mathrm{C}_{2}$ to the guide electrodes $G_{1}$ and $G_{2}$ of a glow-transfer counting tube (dekatron). For $G_{1}, R_{5}$ and $R_{7}$ establish bias; and for $G_{2}$, $R_{6}$ and $R_{8}$ establish bias while $R_{2}$ and $C_{3}$ delay the pulse as shown in Fig. 7. The two overlapping negative pulses cause the glow discharge to transfer rapidly from cathode $K_{0}$ to $G_{1}$, then to $G_{2}$, and as $G_{2}$ returns to its positive bias voltage, the glow moves to the next most negative point, cathode $K_{I}$. The zero cathode is returned to ground through $R_{g}$ so that succeeding stages (decades) may be driven directly from the voltage rise as the glow reaches $\mathrm{K}_{\mathrm{O}}$. Other cathodes and the gulde blas networks may be grounded elther directly or through a normally closed reset switch. The table in Fig. 6 shows component values for two maximum frequericies and various tubes. 

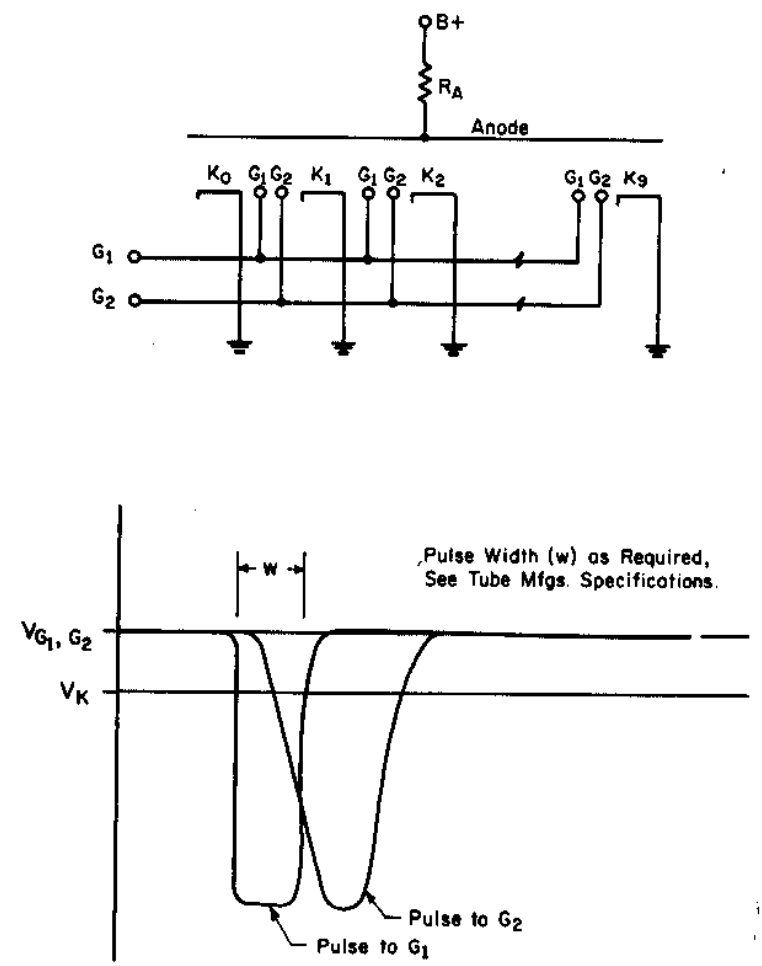

FIG. 7 GLOW-TRANSFER COUNTER TUBE OPERATION 


\section{COUNT RATE METER}

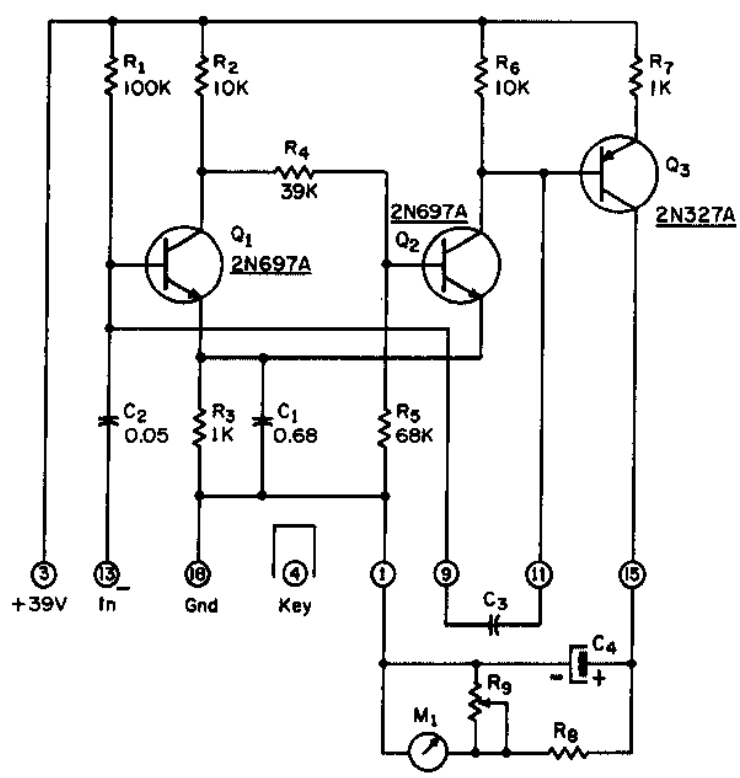

FIG. 8 COUNT RATE METER, PC- 1

The count rate meter (CRM) circuit is the univibrator circuit with a meter drive amplifier $\left(Q_{3}\right)$ added. $Q_{1}$ and $Q_{2}$ form a "oneshot" and operate in the same manner as in PC-5. $Q_{3}$ is a silicon PNP transistor, directly coupled to $Q_{2}$. The gain of this stage (G) is proportional to the ratio of collector load and emitter resistances

$$
G=k\left(\frac{R_{8}+\frac{R_{m} R_{9}}{R_{m}+R_{\theta}}}{R_{7}}\right)
$$

where $R_{m}$ is the resistance of meter $M_{1}$ and $k$ is a constant. Output pulses to the meter circuit are integrated by its parallel combination with a large capacitor $\mathrm{C}_{4}$.

Varying $R_{B}$ in this circuit will vary the integration time constant, but will not affect the voltage developed across the meter and its shunt. For example, let

$$
R_{8}=0 \text { and } \frac{R_{m} R_{9}}{R_{m}+R_{9}}=R_{7}
$$

then

$$
\mathrm{G}=\mathrm{k}
$$


Now let

then

$$
\begin{aligned}
R_{8} & =R_{7} \text { and } \frac{R_{m} R_{9}}{R_{m}+R_{9}}=R_{7} \\
G & =2 k
\end{aligned}
$$

Although voltage across the collector load is now doubled, the voltage across $M_{I}$ is proportional to the rat10

$$
\frac{\left(\frac{R_{m} R_{9}}{R_{m}+R_{\theta}}\right)}{R_{8}+\left(\frac{R_{m} R_{\theta}}{R_{m}+R_{\theta}}\right)}=1 / 2 \quad \text { when } \quad \frac{R_{m} R_{\theta}}{R_{m}+R_{\theta}}=R_{B}=R_{7}
$$

or exactly what it was before $R_{8}$ was added. Thus, the meter voltage is always the same regardless of the $R_{\theta}$ value, even though the integration time constant changes.

Integrated pulses of constant amplitude and width are thus converted to an analog representation of frequency. Full-scale frequency range (or count rate) is determined by $\mathrm{C}_{3}$, which determines pulse width, and by the calibration adjustment $R_{\theta}$. A alngle-range count rate meter may be made by soldering $C_{3}$ and $C_{4}$ directly to the $\mathrm{PC}-1$ socket, but multiple ranges having different time constants require switch-selected components that may be mounted on other boards.

Since recovery time of the CRM multivibrator is finite, two pulses occurring within the total pulse and recovery time (dead t.1me) cannot be resolved. Error due to dead time in random pulse counting is shown by

$$
N_{1}=N(1-N t)
$$

where an actual counting rate of $N$ ylelds an observed rate of $N_{I}$ when $t$ is dead time and $N t \ll 1$. Dead time error for the $P C-I$ clrcult with five ranges is shown in the table of F1g. 9. Actual dead time was determined experimentally by observing the maximum frequency of 1-microsecond pulses that could be resolved at each range sett1ng.

\begin{tabular}{|c|c|c|c|c|}
\hline $\begin{array}{c}\text { Range, } \\
\mathrm{c} / \mathrm{m}\end{array}$ & $c_{3}$ & $\begin{array}{c}\text { Maximum } \\
\text { Count Frequency, } \\
\text { pulses/sec }\end{array}$ & $\begin{array}{c}\text { Deod Time, } \\
\frac{1}{\text { mox count freq }}\end{array}$ & $\begin{array}{c}\text { Maximum Error, } \\
\% \text { full scale }\end{array}$ \\
\hline 30,000 & $0.001 \mu \mathrm{f}$ & 30,000 & $33 \mu \mathrm{sec}$ & 1.7 \\
\hline 10,000 & $0.003 \mu \mathrm{f}$ & 12,000 & $83 \mu \mathrm{sec}$ & 1.4 \\
\hline 3,000 & $0.01 \mu \mathrm{f}$ & 4,000 & $250 \mu \mathrm{sec}$ & 1.3 \\
\hline 1,000 & $0.03 \mu \mathrm{f}$ & 600 & $1.67 \mathrm{msec}$ & 2.8 \\
\hline 300 & $0.1 \mu \mathrm{f}$ & 200 & $5 \mathrm{msec}$ & 2.5 \\
\hline
\end{tabular}

FIG. 9 CRM CHARACTERISTIC TABLE 


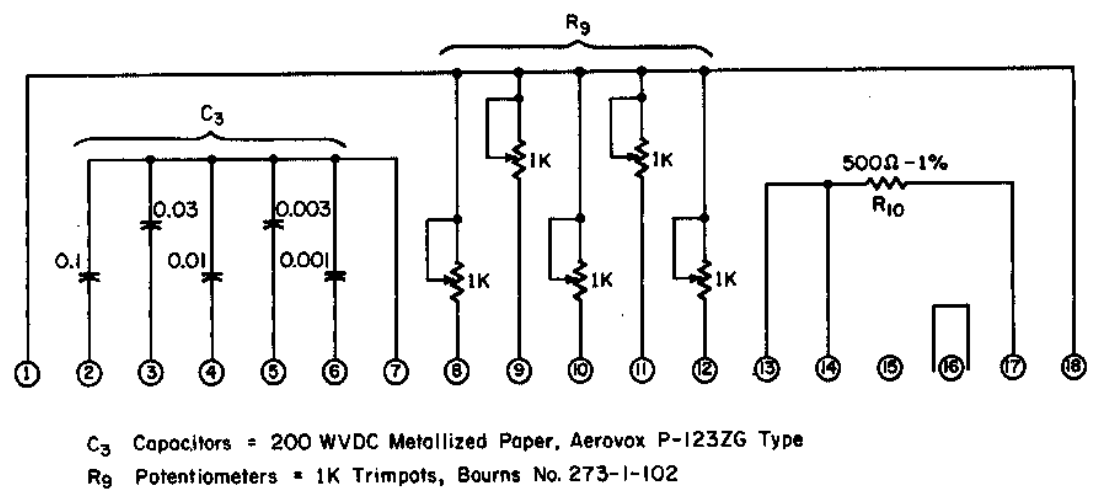

FIG. 10 CRM RANGE, PC.6

PC- 6 is a convenient mounting board for five values of $C_{3}$ and $R_{9}$ in the CRM circuit, with terminals for connection to a selector switch. It also provides a mounting location for a precision resistor that may be connected in serles with the meter to develop a recorder output voltage. For example, a 500-ohm resistor in a 100microampere clrcuit develops 50 millivolts, a standard recorder range. If desired, a recording microammeter may be connected instead of the resistor. Used in conjunction with PC-1, the PC- 6 makes a five-range CRM (FIg. 11 ), and PC-7 provides an individual time constant for each range.

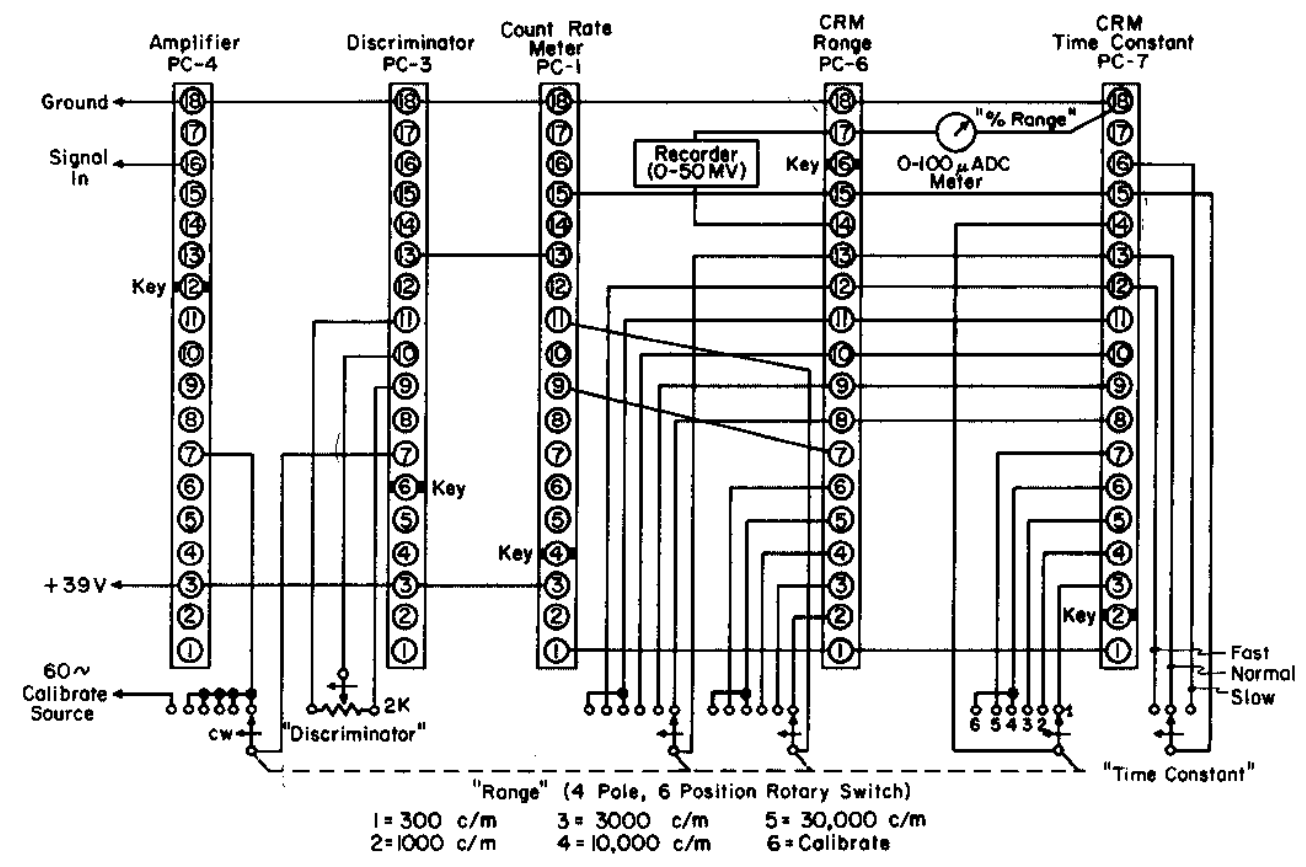

FIG. II SOCKET INTERCONNECTIONS FOR FIVE-RANGE CRM 


\section{CRM TIME CONSTANT}

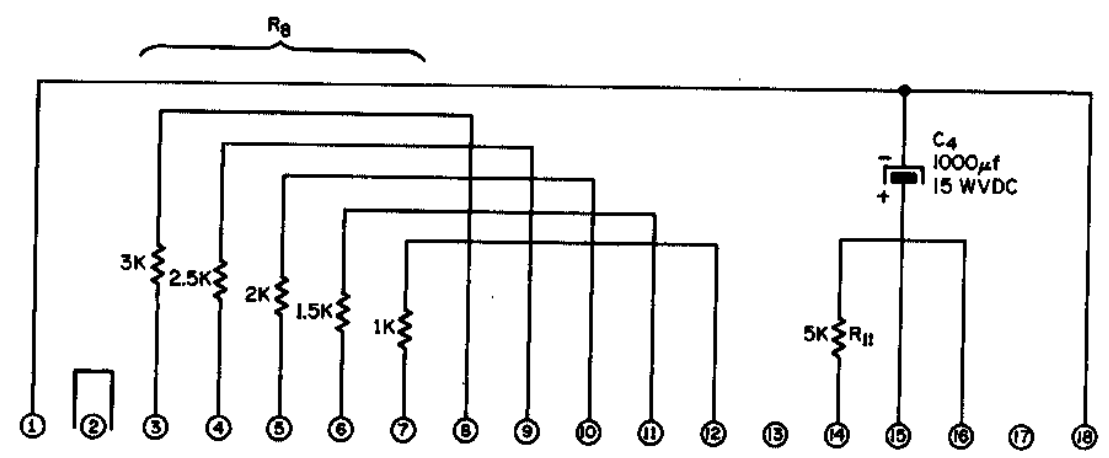

$R_{11}$ a $R_{B}$ Resistors = $1 \%$ Corbon film Types

$\mathrm{C}_{4}$ Capacitor - Tubulor Electrolytic with Wire Leods

FIG. 12 CRM TIME CONSTANT, PC-7

Normally, to prevent flicker of the meter's pointer, the very low counting rates indicated by a count rate meter require a. long integration time constant. The PC-7, which contains the integrating capacitor, permits the selection of any one of five values of $R_{B}$ (in the PC-I clrcult). An additional switch may short this section or connect another 5000 ohms in series with it, providing "slow," "normal," and "fast" time constants as desired. Only in the "fast" position does the time constant not change with range. All resistors are $1 \%$ precision carbon film types. 